\title{
Dual Diagnosis as a Tool for Therapists and Social Workers
}

\author{
Andrzej Lipczyński \\ Jarosław Kinal \\ Institute of Sociology, University of Rzeszow
}

\begin{abstract}
The problem of dual diagnosis described as the first in Poland Lehmann in 1993. He noticed that for people with dual diagnosis is needed different diagnostic and therapeutic-specific approach and that social services (Lehman, 2000; Le hman 1993; Lehman, Myers 1994). Clinical experience suggests the need for a clear separation of this group of patients from both patients and the mentally ill odwykowo. T HAT approach allows to carry out homogeneous diagnostic psychiatric patients. Such ayodrębnienie It is dictated by the difficulties of diagnostic and therapeutic (Siegfried 1998; Sciacca 1991; Lehman, 1998). One clinical term for such a diverse group of patients do not permit a homogeneous diagnostic tests and determine the needs, problems and medical treatment and social services. Interest in this group of patients is not only due to cognitive reasons, but also due to the increasing number of people with dual diagnosis, more effective treatment and social assistance. Another reason is the rapidly growing number of people with $\mathrm{PD}$. This group represents a challenge for physicians, social workers (Crome, Myton 2004; Lehman 2000; Alaja, Sepia1998).Clinical studies confirm the phenomenon of interactivity in which a mentally ill person is at high risk of developing mood-dependent dependence, particularly alcohol and those who are at high risk for mental illness (Lehman 2000).Dual diagnosis is the term defining the clinical coexistence in the same person from one side of a mental disorder, and disorders related to psychoactive substances, mostly drugs and / or alcohol (Abel-Saleh 2004; Crome, Myton 2004). The population of patients with dual diagnosis is large and varies widely in type and severity of the mental illness, the type of psychoactive agents and specific disorders resulting from the adoption of psychoactive substances, psychological and social skills which is obtained support and other factors (Lehman 1996; Ridgely 1987), such as schizophrenia. Severe mental illness (severe mental illness) as a concept which takes into account the clinical diagnosis (diagnosis) the degree of impairment of (disability) and duration of disorder (duration). This criterion includes serious mental breakdowns such as schizophrenia, bipolar affective disorder, depression. These disorders seriously impair people-to-people contact, self-care. Treatment of people with dual diagnosis is a problem because it results from the combination of two extremely different ways of dealing with mental illness and addiction.
\end{abstract}

Keywords: double diagnosis, social work, therapy, social psychology, psychiatry

\section{Introduction}

In 1997, for the first time was describe the possibility of the development of mental illness as a result of substance use, as well as on the ground of mental disorders opportunities addiction These measures (Mc Lella et al. 1997).

The problem of dual diagnosis described as the first in Poland Lehmann in 1993. He noticed that for people with dual diagnosis is needed different diagnostic and therapeutic-specific approach and that social services (Lehman, 2000; Le hman 1993; Lehman, Myers 1994).

Clinical experience suggests the need for a clear separation of this group of patients from both patients and the mentally ill odwykowo. T HAT approach allows to carry out homogeneous diagnostic psychiatric patients. Such ayodrębnienie It is dictated by the difficulties of diagnostic and therapeutic (Siegfried 1998; Sciacca 1991; Lehman, 1998). 
One clinical term for such a diverse group of patients do not permit a homogeneous diagnostic tests and determine the needs, problems and medical treatment and social services.

Interest in this group of patients is not only due to cognitive reasons, but also due to the increasing number of people with dual diagnosis, more effective treatment and social assistance. Another reason is the rapidly growing number of people with PD. This group represents a challenge for physicians, social workers (Crome, Myton 2004; Lehman 2000; Alaja, Sepia1998).

Clinical studies confirm the phenomenon of interactivity in which a mentally ill person is at high risk of developing mooddependent dependence, particularly alcohol and those who are at high risk for mental illness (Lehman 2000).

Dual diagnosis is the term defining the clinical coexistence in the same person from one side of a mental disorder, and disorders related to psychoactive substances, mostly drugs and / or alcohol (Abel-Saleh 2004; Crome, Myton 2004).

The population of patients with dual diagnosis is large and varies widely in type and severity of the mental illness, the type of psychoactive agents and specific disorders resulting from the adoption of psychoactive substances, psychological and social skills which is obtained support and other factors (Lehman 1996; Ridgely 1987), such as schizophrenia.

Severe mental illness (severe mental illness) as a concept which takes into account the clinical diagnosis (diagnosis) the degree of impairment of (disability) and duration of disorder (duration).

This criterion includes serious mental breakdowns such as schizophrenia, bipolar affective disorder, depression. These disorders seriously impair people-to-people contact, self-care.

Treatment of people with dual diagnosis is a problem because it results from the combination of two extremely different ways of dealing with mental illness and addiction.

Therapeutic programs intended for patients with severe mental illness should take into account zy Double diagnosis. Cooccurrence of two diseases is a common phenomenon at the same time and is no exception to. It is important that this fact be taken into account and should not be a surprise to physicians dealing with people with a problem. Me psychic, moreover, in all pro Grams of mental health after You should make the appropriate changes.

Teams specialized in the treatment of one $d$ Disorders are insufficient because they remain Bind many patients without diagnosis, treatment and recovery. In addition, many of the elements These therapeutic programs will not dopaFor the specific problems of patients with po Double recognition.

However, many physicians, patients, and their family members are confronted with very difficult but temporary problems, and for obvious reasons they show discouragement, doubt or despair. Often they do not have sufficient knowledge about the availability of effective treatments and long-term recovery.

Therefore, it is necessary to realize the existence of these phenomena, which will cause the launch of appropriate education. Maybe hope is also a very important element in the process of recovery.

Eevery ill person has a chance to recover No, but the task of doctors is to give him realistic and optimistic information, taking into account the possibility of long-term improvement $O$ health (Corrigan,Salzer 2004; Deegan, 1996;. Roe, D., Chopra, Rudnick, 2004).

Co-occurrence of psychiatric disorders and the use of SP can be characterized by various dependencies

1. The psychological craving is the cause and the SP reaching for a more or less conscious attempt to self-heal;

2. The acquisition of SP produces a psychopathic syndrome and can contribute to the development of a mental illness;

3. The co-occurring disorders are primary, no causal;

4. The present are non-specific genetic and other biological factors and social changes that underlie both disorders (AriesFurga, et al Steinbarth 2004; Abou-Saleh 2004; Lehman 2000; Księżpolska 2006)

Patients with double diagnosis are more likely to suffer from somnolence than those who are addicted without accompanying mental disorders. (Buckley 2006; Salads 1990; Jones 2004). 


\section{Difficulties in the treatment of people with double diagnosis}

There are three basic groups of problems that make it difficult to treat patients with schizophrenia and addiction / psychoactive substances: (1) Economic and social problems. Patients with double diagnosis require much more financial expense than treatment for addicts only. Problems arising from the patient himself. These problems are related to or arising from the occurrence of negative symptoms, cognitive deficits (Bażyński 2002) (2) Problems on the pathway patient therapist (doctor). There are few integrated dual-use patients. The great majority are treated in a traditional way, the treatment strategies are not comprehensive, more focused on the treatment of individual symptoms. The use of confrontational techniques, a model for hindering participation in the treatment of patients dependent on coexisting schizophrenia (Hoff 1999).

It is definitely difficult to assess the co-occurrence of psychiatric disorders and the addiction / abuse of psychoactive substances in children and adolescents. This difficulty consists of a specific clinical picture combined with adolescence, specific symptoms of schizophrenia and psychoactive drugs. Somatic complications resulting from the interaction with psychoactive agents are broadly described in the literature of the subject. Wright, Walker2001;McEvoy, Kitch $n$ 2000; Neiman, Haapaniwmi 2000)

There is a need to create centers with a separate treatment model, which in their therapeutic program will introduce therapy for people with psychoactive substance abuse problems as well as those associated with mental disorders related to personality traits. Co-occurrence of abuse of psychoactive substances and mental disorders is associated with many factors. The type of psychoactive substances used, the time it takes, and the personality traits of the person and the type of mental disorder are of decisive importance. One of the most important elements of the diagnosis is the attempt to assess the relationship between substance abuse and psychopathology. Used for therapeutic interventions in patients with mental disorders associated with psychoactive substance include rehabilitation and treatment of various forms of interaction $p$ [psychosocial inclusive, which aims NAFO Eradication or elimination of causes or symptoms of diseases and disorders. Rehabilitation includes procedures to help you acquire skills and support Wound patients in overcoming difficulties you Those who are suffering from illness or disorder.

Getting back to health means overcoming the disease and returning to a satisfying and fulfilling life, not just mere symptomatic disorder (Bellack 2006; New Freedom Commission on Mental Health 2003). It also improves on taking significant personal life activities and interpersonal relationships as well. Forming an individual sense of hope and autonomy.

\section{Depression and abuse of psychoactive substances}

There is a serious connection between depression and the abuse of psychoactive substances, especially alcohol and heroin. The use of alcohol and heroin significantly aggravates depression and its severity has been demonstrated by the MMPI test

In the treatment of patients with dual diagnosis of psychoactive substance abuse with depressive disorders, latent psychopathological symptoms appear in the final phase of detoxification. This state mobilizes to develop a treatment program utilizing patient knowledge, orientation and insight to integrate personality elements and social functioning. In this regard, it is necessary to include a social worker.

Depending on the depth of depression, a detailed program is required to involve psychiatrists, addiction treatment psychologists and social worker. The whole program is personalized and tailored to the patient's level and capabilities. Behavioral methods, therapeutic interventions directed at the emotional sphere are at this stage validated.

\section{Abuse of psychoactive substances and anxiety}

The symptoms of anxiety are not alien to people abusing psychoactive substances. Overexposed anxiety can be the primary or secondary consequence of their abuse. It is possible to observe a close interaction between the use of psychoactive substances because it experiences strong anxiety, and abuse enhances the symptoms of anxiety. Detoxification is necessary to start therapy. With a low level of anxiety addiction therapists are able to cope. If anxiety has pathologic signs, the therapeutic procedure is different. There is a holistic approach to addressing addiction and mental health. 


\section{Abnormal personality (sociopathy) and abuse of psychoactive substances}

It should be noted that in the current classification of DSM III and later sociopathy is not taken into account, and the concept of antisocial personality has been introduced with the need to appear before the age of 15 certain characteristics. Out of 17 features, at least three must appear before the age of 15 . These characteristics include: frequent truancy, lack of adaptation to school conditions, criminal activity, escape from home, aggressive attitude. When a person reaches the age of 18, three or four of the following symptoms may occur: inability to work, recurrent criminal behavior, failure in marriage, physical abuse, impotence, lying, carelessness. These symptoms should persist for 5 years after age 15 in the absence of identified mental retardation, schizophrenia or other mental illness.

The antisocial personality was found in MMPI studies in substance abuse abusers and co-occurring criminal behavior. Consequently, in a therapeutic program outside of therapy focused on the abuse of psychoactive substances, it focuses on antisocial behavior and behavior.

Persons with antisocial (sociopathic) personality abuse of psychoactive substances can be treated in addiction treatment clinics with a special focus on the socialization process. The patient is responsible for the treatment process. Therapists should use supervision. For this type of patient it is necessary to conclude a very clear, unequivocal contract specifying not only the plan of the activity, but its active participation.

In this program, the program of reintegration of patients into the rhythm of normal social life is also of great importance. It is justified by the patient's life history. Typically, these patients are exposed to antisocial behavior from their youth.

\section{Schizophrenia and abuse of psychoactive substances}

Schizophrenia belongs to a group of mental disorders that can damage the cognitive processes: disorganization of the personality and isolation from the environment. Symptoms of schizophrenia include psychotic states that involve a reduced organization of mental functions. In the course of acute psychosis, the patient loses contact with reality, producing psychopathological symptoms, thinking disorders and speech. As a result, problems in working at work, interpersonal contacts, self care are revealed. (Mirin 1999).

The motivation for taking psychoactive substances for a person suffering from schizophrenia is related to the very subjective sense of the benefits and comfort they give. In general, schizophrenics choose the kind of substance to get the maximum minimize or eliminate symptoms of the disease and to provide intense emotional experience, reduce the effects of medication (.Dixon L, G Haas, 1991; .Dixon L, G Haas, 2001)

Studies often confirm the association between schizophrenia and psychoactive substance abuse. (Allerman Erdlen 1990) This creates a special therapeutic program for these patients because they require a specific treatment that combines psychiatric treatment and psychoactive substance abuse. Detoxification, which is a necessary part of therapy in the case of mentally ill people, is not entirely possible. This is due to the need for medication during schizophrenia. It is also necessary to control coordinated treatment, as patients can often include other drugs. Outpatient treatment can be performed by a trained social worker or social worker. Patients with schizophrenia and at the same time abusive patients do not belong to those who undergo therapy are unstable in treatment. It is also difficult to obtain beneficial therapeutic relationships. To some extent, this results in too much rejection by the psychiatric health care system. Patients who come back to use psychoactive substances are significantly affected by mental illness. It follows that such patients require appropriate help, a specific health care system and the program.

In schizophrenia a lot of emphasis is placed on building relationships of intimacy, tolerance of rejection, lack of directives. In addiction, borders become important

and ii terap confrontational conduct. (Mellibruda J Sobolewska Mellibruda-2006)

In every human being there are biological and genetically transmitted tendencies to create strong emotional bonds with other people. If for some reason occur, especially in the early stages of human development, in later life may be interfering with the development of emotional, there will be an emotional disorder, but the need for them to remain. (LA Pervin, John, OP., 2005; Fonagy P, T. Leigh, 1996). 
Within personal models of thinking and relationships, I and others throughout the course of my life create a bonding system that aims to integrate the experience gained.

J. Bowlby believes that this model is created according to various kinds of rules from the earliest childhood and is interactive. The formation of proper attachment creates an inner conviction that you are a loved one, worthy of love, valid and acceptable, and that the world is full of friendly people open to the needs of others. Otherwise, based on experience, a belief is created that the environment is unworthy of trust. This is in the company of loved ones. Close conducive to the appearance of negative beliefs about the self-image, unworthy of love (Dozier, M., 1990).

Literature a lot of space is devoted to his mother and her relationship with the child and its availability. Relationships and availability would be relevant in the emergence of mental illness, particularly schizophrenia.

A. Ainsworth has identified three styles of behavior that define the bonds that are made between a child and a mother.

Safe style of attachment, evasive and anxiety-ambivalent. The safe style is most optimal for the development of the child, because of the sense of security, self-confidence and trust. This style is created in the relationship between the child and other people, between him and the object of attachment. These are personal cognitive structure ei a kind of cognitive framework through which to appear and processes occur perception of reality, events and relationships with others. Avoidance style does not provide a sense of security. In adult life this style does not provide a sense of security, arouses discomfort and danger. An anxiety-ambivalent style of attachment creates a sense of uncertainty in social relationships, not satisfying the need for closeness. (Marchwicki P., 2005)

In situations of danger, attachment becomes apparent in the search for safety, homeostasis by regulating the intensity of anxiety Children who have failed to create a safe parenting style can try to attach themselves to other people who play an important role in their lives. It is not entirely sure whether adults prefer the style of attachment developed in childhood or whether they have a chance in favorable conditions to change in adulthood. The relationships that arise between a psychiatric patient, especially with a double diagnosis, and the staff members may try to understand in the context of attachment theory. People with dual diagnosis belong to difficult patients. Characteristics for them are: distrust, lack of cooperation, exposing personnel to the patient, interrupting therapy or drop from the disciplinary therapy (Marchwicki P. 1990).

Conducted observations have shown that the neurophysiological sensitivity of the central nervous system to psychoactive agents (psychostimulants) and its relevance to the disclosure of schizophrenia, induced psychosis, and spontaneous occurrence of psychopathological symptoms of the productive type even during abstinence. Psychotic symptoms may also appear in healthy people as a result of stimulants. Kokkinidis, Anisman 1987; Javitt 1981). People with schizophrenia are more likely to experience schizophrenia.

Efforts were made to assess psychotic symptoms in people with schizophrenia and at the same time addicted to psychoactive drugs. Attempts were made to demonstrate the existence of a subtype of schizophrenia directly related to addiction. Compared patients with schizophrenia and using psychoactive substances with those who did not use these remedies. The results indicate that schizophrenics using psychoactive substances have earlier revealed the first signs of the disease and had more, more frequent relapses and more frequent hospitalizations (Silver, Abboud E 1994).

The addiction process in people with schizophrenia is different from the mentally ill. A significant difference is particularly high susceptibility to psychoactive drugs. One reason is the exacerbation of psychotic symptoms and the adoption of psychoactive substances at that time. Causing the significant deterioration of interpersonal relationships. It looks different in abusive people. Their relationships are improving considerably, especially among young people. (Drake, Oscher 1990; Wolford 1999)

The program can be implemented at an elevated hospital ward linked to an environmental unit, day ward, and clinic.

This program should be flexible employing staff with expertise in treating such patients. Each patient should be individually evaluated and possibly have a separate plan and program of treatment that should not be excessive, fixed with the patient. The pharmacological treatment should be supervised. In each case a contract is required in detail.

\section{Treatment stages:}


(1) Interview and diagnostics The basis for initiating any therapy is to perform a diagnostic interview. If there are difficulties then you can get help from a social worker, your immediate family.

(2) Adoption for detoxification Depending on the severity of the disease is determined detoxification program with the determination of doses of psychotropic drugs. With severe psychopathological symptoms, close supervision of staff is required. The time of this stage is not determined in advance. This is a very individual procedure.

(3) Treatment program and their implementation. At the end of the detoxification process allows you to establish pharmacotherapy. Behavioral therapy sessions, individual and group therapy and occupational therapy sessions are also started. The patient is enough in touch to get started Collaboration in everyday activities. Increased competence, stability, ability to use their mental ability to function better.

(4) Stabilization of mental and physical condition. This is an important stage of therapy, because the patient already has social relationships, he works according to his abilities, he is dealing with the requirements. The patient receives reinforcement and supports the desired behavior. Stabilization of health opens the possibility of preparing a rehabilitation plan conditional on the patient's entry into the social environment. Success at this stage depends not only on the patient itself, although it is most important here, but also from the facility the patient will take to further care and a social worker, family assistant. Next step after the discharge from the ward is not the easiest. The patient remains in custody, but much more time outside the rehabilitation center. The patient is required to be subjected to analysis of body secretions (wet) on myocardial rtość psychoactive substances (drugs). Significance is the effect of the social worker, who together with the patient prepares a contract that clearly defines the scope of action. A social worker may maintain contact with a therapeutic center and, in the event of a relapse, mobilizes the patient to seek treatment. The rehabilitation stage provides stabilization in a non-psychiatric ward for patients. Such a solution is advantageous for patients with dual diagnosis and the therapeutic community in which the patient can achieve a sense of normalcy and support (Gestley, Alterman, Melellan, Woody 1990).

\section{References}

[1] Abou-Saleh MT. Dual diagnosis: management within psychosocial context. Adv. Psychiatrist. Treat. 2004; 10: $552-$ 360.

[1] Abuse - present and future directions. 1990.

[2] Addington J., Addington D .: Effect of substance misuse in early psychosis. Br. J. Psychiatry 1998; 172 (sup.): 134136.

[3] Alaja R, Seppa K, Sillanaukee P et al. Physical and mental comorbidity of substance use disorder. in psychiatric Consultations. European Consultation - Liaison Workgroup. Alcohol. Clin. Expres. 1998; 22 (8): $1820-1824$.

[4] B. Pepper, Krishner MC Ryglewicz H .: The young adult chronic patient: an overview of a population. Hosp. Commun. Psychiatry, 1981; 32: 463-469

[5] Batki SL. Drug abuse. psychiatric disorders and AIDS. Dual and triple diagnosis. West. J. Med. 1990; 152 (5): $547-$ 552.

[6] Bażyńska K., Namysłowska I., Żechowski C .: drug abuse during the first episode of depression. Psychiatric News 2002; 5: 17-22.

[7] Brown V, Ridgely MS, Pepper B, Levine IS. The dual crisis - mental illness and substance

[8] Buckley PF. Prevalence and consequences of the dual diagnosis of substance abuse and severe mental illness. J. Clin. Psychiatry. 2006; 67: 5-9

[9] Cantwell R., Brewin J. Glazebrook C. et al .: Prevalence of substance misuse in first-episode psychosis. Br. J. Psychiatry 1991; 174: 150-153

[10] Cantwell R., Brewin J. Glazebrook C. et al .: Prevalence of substance misuse in first-episode psychosis. Br. J. Psychiatry 1991; 174: 150-153.

[11] Caton CLM The new chronic patient and the system of community care. Hosp. Commun. Psychiatry, 1981; 32: 475478

[12] Cochrane Database Syst. Rev. Rev. 2000; (4): CD001088.

[13] Corrigan PW, M. Salzer, Ralph RO, et al .: Examining the factor structure of the re Covery assessment scale. Schizophr. Bull., 2004; 30: 1035-1041

[14] Crome IB, T Myton. Pharmacotherapy in dual diagnosis. Adv. Psychiatrist. Treat. 2004; 10 413-424. 
[15] D. Mueller, Gilden DH . Brown-Séquard syndrome after esophageal Sclerotherapy and crack cocaine use. Neurology, 2002; 58: 1129-1130.

[16] D. Roe, M. Chopra, Rudnick A .: Persons with psychosis as active agents interacting with Their disorder. Psychiatrist. Rehabil. J., 2004; 28: 122-128

[17] Deegan $P$.: Recovery and the conspiracy of hope. Presented at the Sixth Annual Men tal Health Conference of Australia and New Zealand, Brisbane, Australia, September 1996

[18] Dervaux A Bayle F Laqueille X Bourdel MC Borgone MH., Olie JP Krebs MO. Is substance abuse in schizophrenia related to impulsivity, sensation seeking, or anhedonia? Am. J.Psychiatry 2001; 158 (3): 492-494.

[19] Dixon L, G Haas, Weiden P J Sweeney, A. Frances Drug abuse in schizophrenic patients: Clinical correlates andreasons for use. Am. J Psychiatry: 1991; 148: 224-230.

[20] Dixon L .: dual diagnosis of substance abuse in schizophrenia: prevalence and impact on outcomes. Schizophr. Res. 1999; 35 (supl.): 93-100.

[21] Dozier M. Attachment organization and treatment for adult use with serious

[22] Drake RE, Brunette MF, Mueser KT: Substance use disorder and Social Functioning in schizophrenia. In: Mueser KT, Tarrier N. (Eds.): Handbook of Social Functioning in Schizophrenia. Allyn and Bacon, Boston, 1998: 280-289.

[23] Drake RE, Mercer-McFadden C, Mueser KT, et al .: Review of integrated mental health and substance abuse treatment for patients with dual disorders. Schizophr.Bull. 1998; 24: 589-608.

[24] Drake RE, Mueser KT: Psychosocial approaches a dual diagnosis. Schizophr. Bull. 2000; 26: 105-118.

[25] Drake RE, Wallach MA: Moderate drinking among people with severe mental illness. Hosp. Community Psychiatry 1993; 44: 780-782.

[26] E. Drake, F. Oscher, Noordsy D. et al .: Diagnosis of alcohol use disorders in schizophrenia. Schizophr. Bull. 1990; 16: 57-67.

[27] Evans K, Sullivan JM. Dual diagnosis: counseling the mentally ill substance abuser. New York: Guilford Press; 1990.

[28] Fonagy $P$, Leigh T. Relation of attachment status, psychiatric classification and response is psychotherapy. J. Cons. Clin. Psycho. 1996; 64, 1: 22-31.

[29] Gestley LJ, Alterman A, Melellan AT, Woody GE. Anti social personality disorder in patients with substance abuse disorders - a problematic diagnosis. Am. J. Psychiatry 1990; 147.

[30] Gettig JP Grady SE, Nowosadzka And. : Methamphetamine: putting the brakes on speed. J. Sch. Nurs. 2006; 22: 66-73.

[31] Green Al, Tohen MF, Hamer RM, et al .: First episode schizophrenia-related psychosis and substance use disorders: acute response that olanzapine and haloperidol. Schizophr. Res. 2004; 66: 125-135.

[32] Javitt DC: Negative schizophrenic symptomatology and the PCP (phencyclidine) model of schizophrenia. Hillside J. Clin. Psychiatry 1987; 9: 12-35.

[33] JJ Blanchard, Mueser KT, Bellack AS: Anhedonia, positive and negative Affect, and Social Functioning in schizophrenia. Schizophr. Bull. 1998; 24: 413-424.

[34] Jon A. Panos V.: Comorbidity of mental disorders in children and adolescents. Current Opinion in Psychiatry 2005; 18: 429-434

[35] K. Evans, JM Sullivan Dual Diagnosis: Counseling the Mentally III Substance Abuser. Guilford Press, New York 2001.

[36] Kalant $\mathrm{H}$.: The pharmacology and toxicology of "ecstasy" (MDMA) and related drugs. CMAJ 2001; 165: 917-928.

[37] Kokkinidis L., Anisman $\mathrm{H}$.: Amphetamine psychosis and schizophrenia: a dual model. Neurosci. Biobehav. Rev.1981; 5: 449-461.

[38] Krystal JH, D'Souza DC, Madonick S. Petrakis IL: Towards a rational Pharmacotherapy of comorbid substance abuse in schizophrenic patients. Schizophr. Res.1999; 35 (supl.): 35-49.

[39] Księżopolska A Cedro A Pragłowska E. Coexistence of an affective disorder two Polar and addiction to psychoactive substances. Warsaw: CBT Center Publishing; 2006.

[40] LA Pervin, John, OP. Personality - theory and research . Krakow: Jagiellonian University; 2002.

[41] Lehman AF, CP Myers, JW Thompson, E. Corty Implicarions of mental and substance use disorders. A comparison of single and dual pediatric patients. J. Nery. Ment. Dis. 1993; 181 (6) 365-370.

[42] Lehman AF, Myers CP Corty E. Assessment and classification of patients with psychiatry or substance abuse syndromes. Psychiatrist. Serv. 2000; 51 (9): 1119-1125.

[43] Lehman AF. Myers CP Corty E, Thompson, W. J Prevalence and patterns of ,. Dual diagnosis amongpsychiatrie inpatients. Compr. Psychiatry 1994: 35 (2): 106-112. 
[44] Lehman AF: Heterogeneity of person and place: assessing co-occurring mental and addictive disorders. Am. J. Orthopsychiatry, 1996; 66: 32-41

[45] Ley, A., Jeffery DP, S. McLaren, Siegfried N .: programmers Treatment for people with both severe mental illness and substance misuse (Cochrane Review Methodology).

[46] Lubman DI, Sundram S .: Substance misuse in patients with schizophrenia: a primary care guide. Med. J. Aust. 2003; 178 (supl.): 71-75.

[47] Marchwicki P. Psychosocial determinants of attachment styles. Psychol studies. 2005; 5.

[48] MB Bowers Jr., Mazure CM, Nelson JC, Jatlow PI Psychotogenic neuroleptic drug use and response. Schizophr. Bull. 1990; 16: 81-85.

[49] Mc Lellan AT Woody GE. Development of psychiatric illness in drug abusers. Possibile role of drug preference. N.Engl.J.Med. 1997, 301 (24) pp. 1310-1314.

[50] McEvoy AW Kitchen ND Thomas DG: intracerebral haemorrhage and drug abuse in young adults. Br. J. Neurosurg. 2000; 14: 449-454.

[51] Mellibruda J Sobolewska-Mellibruda Z. Integration psychological addiction. Warsaw: Institute of Health Psychology PTP; , 2006.

[52] Menezes PR, S. Johnson, R. Thornicroft et al .: Drug and alcohol problems among Individuals with severe mental illness in south London. Br. J. Psychiatry 1996; 168: 612-619.

[53] Miles H., S. Johonson, amponsah-Afuwape S. et al .: Characteristics of subgroups of Individuals with psychotic illness and a comorbid substance use disorder . Psychiatrist. Serv. 2003; 54: 554-561.

[54] Mirin SM. Psychopathology and substance abuse. The monograph series of the American Psychiatric Press Inc., 1989

[55] Mueser KT, Drake RE, Wallach MA: Dual diagnosis: a review of ethiological theories. Addict. Behav. 1998; 23 : 717- 734.

[56] Mueser KT, Yarnold PR Bellack AS: Diagnostic and demographic correlates of substance abuse in schizophrenia and major affective disorder . Acta Psychiatr. Scand. 1992; 85: 48-55.

[57] Neiman J., Haapaniwmi HM. Hillbom M .: Neurological complications of drug abuse: pathophysiological mechanisms. Eur. J. Neurol. 2000: 7: 595-606.

[58] psychopathological disorders. Dev. Psychopath. 1990; 2: 47-60.

[59] R. Hoff, Rosenheck RA The cost of substance abuse treatment patients with and without comorbid psychiatric disorders. Psychiatrist. Serv. 1999, 50s.1309-1315.

[60] Ram-Furga H-Steinbarth Chmielewska K. The clinical implications of the effect of frequent USER Vanya psychoactive substances nu occurrence of the phenomenon of dual diagnoses Farmakoter. Psychiatrist. Neurol. 2004; 2; 249-255.

[61] Regier DA, Farmer ME, Rae DS, et al .: Comorbidity of mental disorders with alcohol and other drug abuse. Results from the Epidemiologic Catchment Area (ECA) Study . JAMA 1990; 264: 2511-2518.

[62] S. Goswami, Mattoo SK Basu D., Singh G .: Substanceabusing schizophrenics: do they selfmedicate? Am. J.Addict. 2004; 13: 139-150.

[63] Salo R., Nordahl TE Possin K. et al .: Preliminary evidence of reduced cognitive inhibition methamphetamine in dependent Individuals. Psychiatry Res. , 2002; 111: 65-74.

[64] Salyers MP, Mueser KT: Social Functioning, Psychopathology, and medication side effects in relation substance use and abuse in schizophrenia. Schizophr. Res. 2001; 48: 109-123.

[65] Sciacca K. An integrated treatment approach for severely mentally ill indhńduals with substanct disorders. New Dir. Ment. Health Sen '. 1991; 50: 69-84.

[66] Siegfried N. A ofcomorbidity Review: Major mental illness and problemańc substance use. Aust IBD Psychiatry 1998; 32 (5): 707-717.

[67] Silver H. Abboud E .: Drug abuse in schizophrenia: comparison of patients who Began Their drug abuse before first admission with Those Who Began Their abusing drugs after first admission. Schizophr. Res. 1994; 13: 57-63.

[68] Todd J., G. Green, Harrison, M. et al .: Defining a dual diagnosis of mental illness and substance misuse: some methodological issues. J. Psychiatr. Ment. Health Nurs. 2004; 11: 48-54.

[69] Todd J., G. Green, Harrison, M. et al .: Defining a dual diagnosis of mental illness and substance misuse: some methodological issues. J. Psychiatr. Ment. Health Nurs. 2004; 11: 48-54.

[70] Volkow ND , Chang L., Wang GJ, et al .: Higher cortical and subcortical lower metabolism in detoxified methamphetamine abusers. Am. J. Psychiatry 2001; 158: 383-389. 
[71] Wolford G., S. Rosenberg, E. Drake, et al .: Evaluation of methods for detecting substance use disorder in persons with severe mental illness. Psychology of Addictive Behaviors 1999; 13: 313-326.

[72] Wright A., Walker J .: Drugs of abuse in pregnancy . Best Pract. Res. Clin. Obstet. Gynaecol. 2001; 15: 987998Volkow ND, Chang L., Wang GJ, et al .: Association of dopamine transporter reduction with psychomotor impairment in methamphetamine abusers . Am. J. Psychiatry 2001; 158: 377-382. 